\title{
Knowledge and attitudes toward brain death and organ donation in Bojnurd
}

\author{
Sima Sadat Hejazi ${ }^{1}$, Shima Nikbakht ${ }^{2}$, Leila Jouybari ${ }^{3}$, Mehdi Hares Abadi ${ }^{4}$, Davood Davoodi ${ }^{5}$, Tooba Hoseini \\ Azizi $^{1}$, Sepideh Yahyaei ${ }^{6}$
}

\author{
${ }^{1}$ M.Sc. of Critical Care Nursing, Lecturer, Department of Nursing, Bojnurd Faculty of Nursing and Midwifery, \\ North Khorasan University of Medical Sciences, Bojnurd, Iran \\ ${ }^{2}$ M.Sc. Student of Health Services Management, Shirvan Faculty of Nursing and Emam Khomeini Hospital, North \\ Khorasan University of Medical Sciences, Bojnurd, Iran \\ ${ }^{3}$ Ph.D. of Nursing Education, Associate Professor, Nursing Research Center, Golestan University of Medical \\ Sciences, Gorgan, Iran \\ ${ }^{4}$ M.Sc. of Nursing Education, Lecturer, Department of Nursing, Bojnurd Faculty of Nursing and Midwifery, North \\ Khorasan University of Medical Sciences, Bojnurd, Iran \\ ${ }^{5}$ Pharm.D, Razavi Pharmaceutical Services Institute, Mashhad, Iran \\ ${ }^{6}$ B.Sc. of Nursing, Student Research Committee, North Khorasan University of Medical Sciences, Bojnurd, Iran
}

\section{Type of article: Original}

\begin{abstract}
Background: Organ donation in Iran is common. Bojnurd (North Khorasan, Iran) is a multi-ethnic city, and people with different religions and cultures live together and that could be associated with their behavior and attitude towards health-related issues. So far, no study has taken place on brain death and organ donation in the province of North Khorasan.

Objective: The aim of this study was to determine the knowledge and attitudes of citizens of Bojnurd toward brain death and organ donation.

Methods: This cross-sectional study was conducted from March to September 2014, on 380 Bojnurd citizens who were selected through multi-stage sampling. The tool was a researcher-made questionnaire in three parts (demographic information, awareness and attitude surveys), containing 10 questions on awareness and 18 questions on attitude. The questionnaire validity and reliability were confirmed by content validity and Cronbach's alpha (0.76). The data were analyzed by using SPSS version 16, using Chi-square, independentsamples t-test, and Spearman correlation coefficient. Significance level was set at $\mathrm{p}<0.05$.

Results: Three hundred and eighty participants with the average age of $29.91 \pm 9.32$ were studied, of which $55 \%$ were female. The average score of awareness and attitude was $11.42( \pm 2.40)$ and $39.8( \pm 6.01)$ respectively. The awareness of the majority of the people $(63 \%)$ regarding organ donation was moderate and the attitude toward organ donation in the majority $(74.1 \%)$ was poor. In people with poor attitudes, awareness was also lower, and this was statistically significant $(\mathrm{p}=0.047)$.

Conclusion: the attitude towards organ donation was negative in the majority of the citizens. In order to correct the beliefs, develop positive attitude and increase citizens' knowledge, public education is essential.

Keywords: Organ Donation, Brain Death, Awareness, Attitude, Citizens
\end{abstract}

\section{Introduction}

The term brain death was first introduced and defined in the second half of the twentieth century (1), and refers to the complete cessation of the functions of the brain and brain stem, which is irreversible $(2,3)$. In brain death, the patient is not breathing and is unable to respond to internal or external stimuli, and remains in a complete coma. In these circumstances, there is no prospect of a reversion of mentioned functions and the patient only has an

\section{Corresponding author:}

Shima Nikbakht, Shirvan Faculty of Nursing and Emam Khomeini Hospital, North Khorasan University of Medical Sciences, Bojnurd, Iran Tel: +98.5836226623, Email: nikbakht.shima@gmail.com

Received: July 11, 2016, Accepted: January 04, 2017, Published: July 2017

iThenticate screening: December 04, 2016, English editing: February 20, 2017, Quality control: April 12, 2017

(C) 2017 The Authors. This is an open access article under the terms of the Creative Commons Attribution-NonCommercialNoDerivs License, which permits use and distribution in any medium, provided the original work is properly cited, the use is non-commercial and no modifications or adaptations are made. 
autonomous heartbeat which could be temporarily sustained by ventilator for a few hours up to several days (4). Human organ transplantation in cases of irreversible organ failure has been a matter of debate in social circles since a long time ago and various aspects including scientific, moral, religious, political and legal aspects have been addressed (4) and currently, after so many ups and downs, it is considered as a life-saving operation in patients with end-stage organ failure, and one of the most effective treatments or sometimes the only treatment for many diseases that can improve the quality of life in patients $(2,5,6)$. Although some studies about organ donation in Iran raise its contradiction to religious rules as the most important reason cited by its opponents for getting organ donation cards, organ transplantation is not prohibited by Islamic law, and many of the great religious scholars in the Islamic countries have confirmed this (4). For many consecutive years, kidney and corneal transplants needed for patients had been supplied from outside, which were often of poor quality and high expense. However, in March 2000, legislation on organ harvesting from the cadaver was passed in congress, and organ donation from brain dead patients was legalized (5-7). In Iran, it is estimated that from every ten car accidents, one person is killed and out of every 100 deaths one brain death occurs (8), in which there is no possibility of rebirth for these patients, however, their organs may be transplanted into another person's body (2). Statistics of organ donation in Iran is about two per million (9) and less than 10 percent of brain dead patients are organ donors (10), while in European countries, this proportion reaches twenty in a million and in some countries, such as Spain, reaches 35 in a million (9). These statistics prove that only a small proportion of brain-dead people in Iran are voluntary to organ donation which does not meet the people in need $(11,12)$. The lack of proportionality between the statistics of donated organs and organs required for transplantation is a major problem in the field of organ transplantation (5-7). According to statistics in the USA in 2004, 95,000 patients were on the waiting list for organs, while only 27,000 transplants were performed that year (13). Regarding this, and despite the fact that America and Europe are facing problems in organ transplants as well, which is because of the shortage of donated organs, in this regard, significant differences still exist between these countries and Asian countries (14). Despite the conflicting results of some studies, there are still many individuals who do not have a positive attitude about organ donation, since organ donation rate is much lower than global statistics in practice, which is perhaps due to some new and unknown aspects of this phenomenon. In most countries, the process of organ donation depends on the decision of the family of the deceased (15), and the refusal of families to give consent for organ donation is the biggest obstacle $(11,12)$. What the most important factors are, in patients' families' refusal to donate organs from brain-dead patients are still elusive and under dispute of medical science researchers. Studies show that two categories of factors affect the decision on organ donation. One category could be modified by public education in society and the other category could be modified by providing good conditions at the time of the request which meets supportive and informative needs of the family, and understanding of their critical condition (10). In this regard, Niazi, quoting from a study by Zohoor and Bozorg Magham, declared that only slightly more than half of the surveyed peopled believed that returning back to life is impossible in brain dead patients, which indicates a lack of awareness in this regard (16). On the other hand, in a study by Pourhosseini et al., the effect of education on enhancing both the awareness and attitude toward organ donation in brain death, is significant and evident (17). Thus, it is necessary to carry out further research in recognizing the weakness points in the awareness and attitudes toward the issue and implement an educational planning in the field that builds up the culture of organ donation from brain dead patients and establishes the belief that brain death is, in fact, the death in its general sense (7). Improving public confidence in the medical system for accepting the diagnosis of brain death by related families in the first place will prevent the unnecessary use of beds in the intensive care units. Regarding the limitations in the supply of beds and the complicated and expensive care, organ donation makes it possible to efficiently and effectively allow other people in need to use the facilities. This, in turn, will affect countries' expenses through reducing the cost of health care. Furthermore, by using donated organ transplants, it would be possible to revive the lives of several patients, and life expectancy would increase (5-7). Bojnurd is a multi-ethnic city and people with different religions and cultures live together, and being of different ethnicity and culture could be associated with their behavior and attitude towards health-related issues. So far, no study has taken place on brain death and organ donation in the province of North Khorasan. Thus, this study has been implemented with the aim of determining the awareness and attitudes of Bojnurd citizens regarding brain death and organ donation.

\section{Material and Methods}

The present study is a cross-sectional research which was performed from March to September 2014 to assess the awareness and attitudes of Bojnurd citizens towards organ donation. The Sample size was determined 380 cases regarding the estimate of a positive attitude towards organ donation which had been obtained as $43 \%$ in the study by Zohoor and his colleagues (14) and also according to the values obtained from Cochran formula. The study population consisted of Bojnurd citizens over 18 years old who had the ability to read and write. Multi-stage sampling was used to collect information from Bojnurd by firstly dividing it into five regions, then from each region 
a district, and from each district, one street was selected and continued until reaching the desired sample size. Eventually, 76 people were selected from each region. After obtaining approval from the Ethics Committee of North Khorasan University of Medical Sciences and obtaining the necessary consent from citizens, and after explaining the purpose of the study and assurance regarding compliance in maintaining information integrity, questionnaires were completed by citizens and in collaboration with researchers. The tool used in this study was a questionnaire with three parts, which was prepared by the researchers after reading resources provided. And in order to determine content validity, it was presented to the eight faculty members of North Khorasan University of Medical Sciences and Golestan University of Medical Sciences, two citizens and two medical students. After removing one question in the awareness part of the questionnaire, and applying some changes, it was confirmed by them. The reliability of the questionnaire was estimated as 0.76 by Cronbach's alpha coefficient. The first part of the questionnaire included demographic information (age, sex, religion, income level, ethnicity and education, level of the individual's information about organ donation, source of information, history of transplantation or organ donation among relatives, having organ donation card and desire for having organ donation card and knowing the fatwa by Marja). The second part contained ten questions on awareness in tri-variables Likert scale which was designed as "correct, incorrect and do not know", so that the answer "correct" scores two, "do not know" scores one and the answer "incorrect" scores a zero, with the maximum score of twenty and a minimum score of zero. The higher the score obtained is, the higher a person's level of awareness would be. The third part of the questionnaire was the assessment of attitude that includes questions about the acceptance or rejection of organ donation and the corresponding reasons, attitudes towards the spiritual effect of the donor on the recipient, willingness to organ donation in cases of brain death, tendency to receive a donated organ as needed and family attitudes towards organ donation, which was designed in the form of a four-variable Likert questionnaire including the following items: strongly agree (score one), agree (score two), disagree (score three) and strongly disagree (score four). The higher the obtained score is, the more negative attitudes toward brain death and organ donation would be. Data analysis including descriptive statistics, Chi-square, Spearman correlation coefficient and Independent-samples t-test was performed using SPSS version (SPSS Inc., Chicago, Illinois, USA) with the significance level set at $\mathrm{p}<0.05$.

\section{Results}

In this study, awareness and attitudes toward brain death and organ donation were studied in 380 cases of Bojnurd citizens. Two hundred and nine (55\%) of the participants were female and the mean age was $29.91 \pm 9.32$. The most frequent ethnicities among the participants were 211 cases (55.5\%) Fars, 98 cases (25.8\%) Kormanj, and other cases were Tork and Turkmen respectively. The highest level of education was Bachelor's in 153 participants (40.3\%) and the rest were diploma, under diploma and associate degree, respectively. In terms of income, the majority including 264 people $(69.5 \%)$ had a moderate income. On questioning the level of information on organ donation, 249 $(65.5 \%)$ declared somewhat and the rest answered low, high and not having information respectively. Sources of information in $242(66.5 \%)$ of the participants were the broadcasting media and for the rest, were newspapers and books, friends and relatives and scientific conferences respectively. The majority of the participants $(88.2 \%)$ did not have a history of organ donation among relatives and acquaintances. The majority of the participants (87.4\%) had no history of organ transplantation among relatives and acquaintances. Most subjects (91.6\%) did not have an organ donation card, while the majority $(60.4 \%)$ was willing to receive an organ donation card. The majority of Bojnurd citizens (75.7\%) were unaware of the Maraji's Fatwa about organ donation. Answers of participants to the attitudes and awareness questionnaires are presented in Tables 1 and 2 . The mean and the standard deviation of awareness score were $11.42 \pm 2.40$ respectively. There was no significant relationship between awareness and age, gender, religion and having an organ donation card, while there was a significant relationship between the desire to get an organ donation card and awareness, so that those who desired to get their organ donation cards, got higher score on their awareness questionnaire $(\mathrm{p}<0.05)$. The mean and standard deviation of attitude score were $39.8 \pm 6.01$. The attitude of the majority of participants (74.1\%) to organ donation was unfavorable. Results of correlation assessment between awareness and attitude showed that the correlation coefficient between the two variables was 0.104 and it was negative. So, the higher the attitude score is, the lower the awareness level is (A high score on the questionnaire represents a weaker attitude) and this association was statistically significant $(\mathrm{p}=0.047)$. There is no relationship between the attitude and participants' age and educational level. Also, no significant relationship was seen between religion and attitude. There is no significant relationship between participants' ethnicity and their awareness score nor with their attitude. While there was a relationship between attitude and level of income ( $\mathrm{p}=0.012)$, and using Tukey's test it was found that both high and low-income levels are related to the attitude, so that people with highincome levels had lower attitude and conversely, people with lower income levels had a higher attitude. There was a significant difference between the attitude score of people who have had organ donation cards and people who did 
not have the card $(\mathrm{p}=0.001)$. There was also a significant difference between the attitude of people who were willing to get organ donation card and those who were not willing get their organ donation cards $(p=0.00)$.

Table 1. Frequency of Bojnord citizens' answers to questions of awareness section about brain death and organ donation

\begin{tabular}{|l|l|l|l|}
\hline Questions & Correct & Incorrect & $\begin{array}{l}\text { Do not } \\
\text { know }\end{array}$ \\
\hline 1- Brain death is different from coma. & 76.1 & 11.6 & 12.4 \\
\hline 2- In the event of brain death, all organs can be donated. & 21.8 & 62.9 & 15.3 \\
\hline 3- There is also the possibility of organ donation in the event of natural death. & 20.3 & 59.2 & 20.5 \\
\hline 4- There is the possibility of returning to life in people with brain death. & 54.5 & 22.6 & 22.6 \\
\hline $\begin{array}{l}\text { 5- According to the Holy Quran, to revive a person is vital to all humanity, } \\
\text { organ donation is an example of resuscitation. }\end{array}$ & 72.9 & 3.9 & 32.2 \\
\hline 6- Sell or donate every member of the body is allowed to be optional. & 16.1 & 58.2 & 25.8 \\
\hline 7- All Islamic scholars permitted to consider organ donation to save lives. & 7.6 & 40.8 & 51.6 \\
\hline 8- Organ transplantation is possible between sexes and races. & 60 & 13.4 & 26.6 \\
\hline 9- Organ donation is contrary to religion and Sharia. & 62.6 & 16.1 & 21.3 \\
\hline 10- Parental consent is required for organ donation. & 62.4 & 32.2 & 14.5 \\
\hline
\end{tabular}

Table 2. Frequency of Bojnord citizens' answers to questions of attitude section about brain death and organ donation

\begin{tabular}{|l|l|l|l|l|}
\hline Questions & $\begin{array}{l}\text { Strongly } \\
\text { Agree }\end{array}$ & Agree & Disagree & $\begin{array}{l}\text { Strongly } \\
\text { Disagre }\end{array}$ \\
\hline 1- Organ donation is a godly and moral right. & 62.9 & 31.3 & 4.2 & 1.6 \\
\hline $\begin{array}{l}\text { 2- The organ donors' moods can affect the mood of the } \\
\text { receiver. }\end{array}$ & 21.1 & 41.3 & 30.3 & 7.4 \\
\hline $\begin{array}{l}\text { 3- Financial need is an important impetus for organ } \\
\text { donation. }\end{array}$ & 8.2 & 26.1 & 50.7 & 15.0 \\
\hline $\begin{array}{l}\text { 4- The survival and vitality in others, is an important } \\
\text { impetus to organ donation. }\end{array}$ & 36.3 & 57.6 & 5.0 & 1.1 \\
\hline $\begin{array}{l}\text { 5- Obtaining heavenly rewards is an important impetus to } \\
\text { organ donation. }\end{array}$ & 48.4 & 39.7 & 9.7 & 2.1 \\
\hline 6- In the event of brain death I donate all my organs. & 48.0 & 31.9 & 13.2 & 6.9 \\
\hline $\begin{array}{l}\text { 7- Sense of altruism is an important impetus to organ } \\
\text { donation. }\end{array}$ & 37.6 & 52.4 & 7.9 & 2.1 \\
\hline $\begin{array}{l}\text { 8- Organ donation is effective in reducing the loss of the } \\
\text { deceased. }\end{array}$ & 25.3 & 47.9 & 21.1 & 5.8 \\
\hline $\begin{array}{l}\text { 9- Even if organ donation is not accepted by the general } \\
\text { public, still do it. }\end{array}$ & 32.1 & 43.7 & 18.2 & 6.1 \\
\hline 10- If I need to graft sometimes, I'll get it. & 37.6 & 54.5 & 5.3 & 2.6 \\
\hline $\begin{array}{l}\text { 11. Interest in the recipients is an important impetus to } \\
\text { organ donation. }\end{array}$ & 22.4 & 41.7 & 29.3 & 6.6 \\
\hline $\begin{array}{l}\text { 12. Disfiguration of a dead body is a factor to avoid organ } \\
\text { donation. }\end{array}$ & 9.2 & 21.1 & 50.8 & 18.9 \\
\hline $\begin{array}{l}\text { 13. Organ donation is incompatible with the natural course } \\
\text { of life and death. }\end{array}$ & 6.8 & 25.9 & 51.9 & 15.4 \\
\hline 14. Because of the interest in the organ, donation is refused. & 7.4 & 21.1 & 48.9 & 22.6 \\
\hline 15. My family encourages me to donate my organs. & 7.1 & 30.3 & 46.8 & 15.8 \\
\hline 16. I talk about organ donation with my friends. & 16.1 & 52.4 & 24.2 & 7.4 \\
\hline 17. I encourage others to donate their organs. & 15.8 & 51.6 & 25.3 & 7.4 \\
\hline 18. I'd like to keep my body intact after death. & 10.3 & 17.1 & 41.6 & 31.1 \\
\hline
\end{tabular}

\section{Discussion}

This study was designed to assess the awareness and attitudes of Bojnurd citizens toward brain death and organ donation. The results of this study showed that in almost half of those surveyed, awareness about brain death and 
organ donation was in the moderate range. In a study by Zohoor et al., less than half of the surveyed men and women had sufficient awareness of organ donation and brain death (14). Half of those surveyed in the present study believed that the returning to life in brain-dead patients is impossible. In a study by Boroumand and Asghari on citizens of Tehran, the majority of those surveyed had the "correct" answer to this question (18). On the other hand, the majority of subjects in Boroumand et al.' study, believed that rebirth after brain death could be possible. In the study by Zohoor and Bozrgmagham less than half of the studied people deemed that rebirth after brain death is impossible $(14,19)$, which is different from the results of the present study. Moreover, about half of the participants in a study by Alizadeh Taghiabad on students of Islamic sciences, also did not know the answers to these questions (9). The majority of people in the present study have mentioned parent's permission as a necessity for organ donation, while in Boroumand and Asghari's study, most surveyed people from Tehran did not (18), which is distinctive from our results. Moreover, in the current study, most participants chose the answer "I do not know" for the question about Maraji's opinion on organ donation, which was in concordance with the results of Boroumand et al., (19). In this study, the majority of subjects declared television as their source of information. Television was also the main source of information in other studies including studies by Alizadeh Taghi Abad et al. on students of nursing and other majors, the study by Zohoor and BozorgMagham, the study by Alghanim on urban and rural residents of Saudi Arabia $(9,14,20)$ and in the study by Mithra et al. on Hindi citizens (21). The Majority of the participants considered organ donation as a charitable activity and earning heavenly rewards was considered an important incentive. In the Zohoor and Bozorg Magham study, the great majority of Tehrani people believed that humanitarian considerations as well as earning the hereafter reward are the most important incentives for organ donation (14). In the study by Arjmand et al., the majority of participants who were receiving organ donation cards considered humanity as the important motivation for organ donation (22). In a study by Zohoor and Piri, the most important reasons for supporting organ donation by nurses and physicians, were saving the recipient's life, humanitarian aid and performing a charitable activity (4). The majority of those surveyed in this study had a tendency for organ donation, which was in line with results obtained by Boroumand et al., Shahbazian et al. and Alghanim's study on urban residents in Saudi Arabia $(19,20,23)$. More than half of urban residents of Islamabad, Pakistan in a study by Maroof et al. had a tendency to donate organs (24). Moreover, the majority of doctors and nurses in the study by Zohoor and Piri, the majority of nursing students and students who studied Islamic sciences in the study of Alizadeh TaghiAbad et al. and the majority of doctors, nurses and emergency medical personnel in the of study Alsaied et al. from Qatar also agreed about organ donation $(4,9,25)$. The results of a 12 -year survey by Bilgel et al., conducted in Turkey, have shown that about half of the citizens surveyed are willing to donate organs (26). While only about half of the Hindi people studied by Mithra et al. have indicated willingness for organ donation (21). In this study, we tried to include citizens in all groups of ages, however, since younger people had better cooperation, the mean age of the subjects was in the range of youth, which was a limitation for the study. Also, the study did not investigate the causes of unwillingness to donate organs, the reasons of not receiving the donor card and whether citizens are familiar with the laws in the field of organ donation or not, which was another limitation of the study.

\section{Conclusions}

The results of this study suggest that public awareness about brain death and organ donation is on a moderate level and the attitude is negative. The importance of these findings is understanding the need of public education improvement in order to familiarize people with brain death and brain death criteria and its differences with similar medical conditions, to increase public awareness, cultivate the right attitude and eventually promote decisions based on correct beliefs. Achieving this goal could be very helpful, considering the important role of the media, especially the broadcasting media which was the most important source of information in this study and similar studies about organ donation. It is highly suggested that the future studies with analytical methods, evaluate the factors influencing attitudes to organ donation, barriers and solutions, and strategies for promoting awareness, attitude, and motivation of citizens toward organ donation.

\section{Acknowledgments:}

We gratefully acknowledge the Vice Chancellor of Research, North Khorasan University of Medical Sciences for financial support through grant number 734 / P / 92. The authors deem themselves necessary to acknowledge the collaboration of all Bojnurd participant citizens and Dr. Sanagoo (Nursing Research Center, Golestan University of Medical Sciences).

\section{Conflict of Interest:}

There is no conflict of interest to be declared. 


\section{Authors' contributions:}

All authors contributed to this project and article equally. All authors read and approved the final manuscript.

\section{References:}

1) Abedi H, Mohammadi dastja M, Abdeyazdan Gh. The Experience of Brain Death Patients' Families Regarding Communication and Familiarity with the Family and the Receptor of the Body Tissue. Knowledg and Research in applied Psychology. 2012; 13(47): 90-8.

2) Khoddami Vishteh HR, Ghorbani F, Ghobadi O, Shafaghi SH, Barbati ME, Rostami Louyeh A, et al. Causes and follow up outcomes of brain dead patients in Shahid Beheshti University of Medical Sciences Hospitals. Pajouhandeh. 2010; 15(4): 171-8.

3) Abbasi MK, Kalhornia Golkar M. Brain Death not certain death and not life; special condition in light of Modern Biomedical Technologies. Med law. 2013; 7(24): 47-64.

4) Zohoor AR, Piri Z. Attitude of physicians and nurses of intensive care units to organ transplantation with brain dead in the hospitals affiliated with Iran University of medical science (Tehran-2003). Razi j Med Sci. 2004; 11(39): 97-105.

5) Aghayan H, Arjmand B, Emami-Razavi H, Jafarian A, Shabanzadeh A, Jalali F, et al. Organ donation workshop - A survey on nurses'knowledge and attitudes toward organ and tissue donation in Iran. Int J Artif Organs. 2009; 32(10):739-44. PMID: 19943235.

6) Abbasi Dolatabadi Z, Farahani B, Fesharaki M, Najafizadeh K. Effect of education about brain death and organ donation on attitude and knowledge of nursing students. Iran J Crit Care Nurs. 2010; 3(3): 109-12.

7) Abdullahi M, ShokraiiFard L. Sociological analysis of organ and tissue donation after brain death among Iranians citizens. Journal of Social Sciences. 2007; (37): 1-38.

8) Ghadipasha MN, Nikian YA, Salehi M, Tajaldini Z. The study of physicians Attitude concerning organ donation and the level of information about laws and sunctions and the procedure in the brain death. IJFM. 2008; 14(2): 112-16.

9) Alizadeh Taghiabad B, Hasanzadeh F, Rayhani T, Karimi H. Comparing Attitudes of Nursing Students and Students of Islamic Sciences Regarding Organ Donation after Brain Death in Mashhad in 2008. Modern Care J. 2014; 11(1): 63-70.

10) Emdadi S, Jalilian F, Shiri M, Mirzayi Alavijeh M, Morshedi M, Ahmad panah M, et al. The Relationship Between Subjective Norms and Registered Volunteer Organ Donors Among Students of Hamadan University of Medical Sciences. IJFM. 2012; 17(4): 217-24.

11) Ahmadian SH, Haghdoost AA, Mohammadalizadeh S. Effective Factors on the Decision of Families to Donate the Organs of their Brain Dead Relatives. J Kerman Univ Med Sci. 2009; 16(4): 353-63.

12) Zakyaei S, Motevalizade S. Brain death and organ donation. J Gorgan Uni Med Sci. 2007; 9(2): 5-6.

13) Bapat U, Kedlaya PG. Gokulnath Organ donation, awareness, attitudes and beliefs among post graduate medical students. Saudi J Kidney Dis Transpl. 2010; 21(1): 174-80. PMID: 20061720.

14) Zohoor A, BozorgMagham M. Attitude of tehranian citizens to organ transplantation and organ donation in brain death. J Ardabil Uni Med Sci. 2003; 2(6): 29-35.

15) Manzari Z, Mohammadi A, Heidari A. Factor influencing organ donation decisions by brain death patients' families: a qualitative study. Payesh. 2012; 11(6): 913-25.

16) Niazi M, Shirazi M. The role of social and cultural factors on organ donation among citizens Kashan. J Contemp Sociolog. 2010; 2(2): 51-82.

17) Azmandian J, Shokouhi M, Poorhoseini S, Mirzaei M. Study of education effect on nurses' knowledge and attitudes about organ donation at the time of brain death. Iran J Crit Care Nurs. 2013; 6(1): 11-20.

18) Boroumand MA, Asghari F. Do Tehran citizens agree with organ donation from a brain-dead family member? J Med Ethics Hist Med. 2012; 5(1): 51-8.

19) Boroumand M, Parsapoor A, Asghari F. Public opinion of organ donation: a survey in Iran. Clin Transplant. 2012; 26(5): 500-4. doi: 10.1111/ctr.12001.

20) Alghanim SA. Knowledge and Attitudes toward Organ Donation: A Community Based Study Comparing Rural and Urban Populations. Saudi J Kidney Dis Transpl. 2010; 21(1): 23-30. PMID: 20061688.

21) Mithra P, Ravindra P, Unnikrishnan B, Rekha R, Kanchan T, Kumar N, et al. Perceptions and attitudes towards organ donation among people seeking healthcare in tertiary care centers of coastal South India. Indian J Palliat Care. 2013; 19(2): 83-7. doi: 10.4103/0973-1075.116701. PMID: 24049347, PMCID: PMC3775029. 
22) Arjmand B, Aghayan H, Goodarzi P, Emami Razavi H. Jafarian A. knowledge and attitudes of members and tissue donation card recipients of donated organs and tissues in the iranian bank of transpalnatation products. J Med Counc I.R Iran. 2008; 26(1): 30-5.

23) Shahbazian H, Dibaei A, Barfi M. Public attitudes toward cadaveric organ donation: a survey in Ahwaz. Urol J. 2006; 3(4): 234-9. PMID: 17559048.

24) Maroof S, Kiyani N, Zaman Z, Gul RK, Nayyar S, Azmat A. Awareness about organ donation especially kidney donation in Nurpur Shahan, a rural community area in Islamabad, Pakistan. J Pak Med Assoc. 2011; 61(68): 828-32. PMID: 22356017.

25) Alsaied O, Bener A, Al-Mosalamani Y, Nour B. Knowledge and attitudes of health care professionals toward organ donation and transplantation. Saudi J Kidney Dis Transpl. 2012; 23(6): 1304-10. doi: 10.4103/1319-2442.103585. PMID: 23168874.

26) Bilgel H, Sadikoglu G, Goktas O, Bilgel N. A survey of the public attitudes towards organ donation in a Turkish community and of the changes that have taken place in the last 12 years. Transpl Int. 2004; 17(3): 126-30. doi: 10.1007/s00147-003-0680-5. PMID: 14745490. 